\section{P72 MATURATION OF SILDENAFIL CLEARANCE IN PREMATURELY BORN INFANTS WITH BPD ASSOCIATED PULMONARY HYPERTENSION}

${ }^{1} \mathrm{H}$ Nikrawesh*, ${ }^{1} \mathrm{AGJ}$ Engbers, ${ }^{1,2} \mathrm{~S}$ Völler, ${ }^{3} \mathrm{SHP}$ Simons, ${ }^{4} \mathrm{BCP}$ Koch, ${ }^{1,5} \mathrm{CAJ}$ Knibbe, ${ }^{3} \mathrm{KMM}$ Reiss, ${ }^{3,6} \mathrm{RB}$ Flint. ${ }^{1}$ Department of Systems Biomedicine and Pharmacology; ${ }^{2}$ Department of BioTherapeutics, Leiden Academic Centre for Drug Research, Leiden University, Leiden; ${ }^{3}$ Department of Paediatrics, Division of Neonatology, Erasmus MC Sophia Children's Hospital; ${ }^{4}$ Department of Hospital Pharmacy, Erasmus Medical Center, Rotterdam; ${ }^{5}$ Department of Clinical Pharmacy, Sint Antonius Hospital, Nieuwegein; ${ }^{6}$ Department of Pharmacy, Erasmus Medical Center, Rotterdam, The Netherlands

\subsection{6/archdischild-2019-esdppp.110}

Background Sildenafil is used as an off-label treatment for bronchopulmonary dysplasia (BPD) associated pulmonary hypertension in prematurely born infants. As there is only limited information on the pharmacokinetics (PK) of sildenafil in this population, the aim of this study is to investigate the PK of sildenafil in prematurely born infants with BPD associated pulmonary hypertension.

Method In this multicentre study, a population PK model for sildenafil in prematurely born infants was developed based on samples obtained using opportunistic sampling during clinical use of sildenafil. Data of seven subjects (42 plasma samples) were analysed by nonlinear mixed-effect modelling (NON$\mathrm{MEM}^{\circledR}$ 7.3). Median (range) gestational age (GA) was 26.1 (24.1-27.6) weeks, current bodyweight 1960 (632-3157) grams, birthweight $635(465-1125)$ grams and postnatal age (PNA) at start of therapy 64.9 (10.9-89) days. The median (range) treatment duration was 4.9 (1.6-13.1) weeks, with six subjects receiving oral doses of median $2.6 \mathrm{mg} / \mathrm{kg} / \mathrm{day}(1.5-$ 5.3 ) in three doses and one subject receiving oral and intravenous doses of $6.7 \mathrm{mg} / \mathrm{kg} /$ day in two doses.

Results The plasma concentration time profiles of sildenafil were best described by a one compartment model. Clearance (CL) and volume of distribution (Vd) for a child with a PNA of 64.9 days and bodyweight of $1.96 \mathrm{~kg}$ was $4.42 \mathrm{~L} / \mathrm{h}$ ((RSE) $11 \%)$ and $29.5 \mathrm{~L}(32 \%)$, respectively. PNA was found to significantly influence CL, resulting in an increase of $10.7 \%$ in a week, and $43 \%$ in a month for a 65 -day old infant. No other covariates (i.e. bodyweight, birthweight, GA, postmenstrual age and sex) were identified for CL or Vd.

Conclusion In this PK study, we characterised the pharmacokinetics of sildenafil in prematurely born infants and found that clearance increases with PNA. Due to the limited sample size in this study, further research in a larger population is needed to extend these findings.

Disclosure(s) Nothing to disclose

\section{P73 PAEDIATRIC POPULATION PHARMACOKINETIC MODELING FOR GENTAMICIN - IS THE CURRENT DOSE RECOMMENDATION JUSTIFIED?}

${ }^{1} \mathrm{P}$ Paioni*, ${ }^{1} \mathrm{C}$ Berger, ${ }^{2} \mathrm{SD}$ Krämer. ${ }^{1}$ Division of Infectious Diseases and Hospital Epidemiology and Children's Research Center, University Children's Hospital Zurich; ${ }^{2}$ Biopharmacy/Radiopharmaceutical Sciences, Institute of Pharmaceutical Sciences, Department of Chemistry and Applied Biosciences, ETH Zurich, Zurich, Switzerland

\subsection{6/archdischild-2019-esdppp.111}

Background Monitoring of gentamicin serum trough level (Cmin) is standard practice in children to prevent toxicity by accumulation ${ }^{1}$. Cmin $<2 \mathrm{mg} / \mathrm{L}$ are recommended. Peak serum concentration (Cmax) is not routinely measured although
Cmax between 10 and $12 \mathrm{mg} / \mathrm{L}$ have been recommended balancing efficacy and toxicity ${ }^{2,3}$. We aimed to develop a population pharmacokinetic (PK) model for gentamicin in children to optimise current dosing regimens.

Methods All patients receiving once daily intravenous gentamicin $(5 \mathrm{mg} / \mathrm{kg}$ in children $<7$ days and $7.5 \mathrm{mg} / \mathrm{kg}$ in children $>7$ days of age) at the University Children's Hospital Zurich between 10/2017 and 01/2019 were eligible for this study. Children with cystic fibrosis and renal replacement procedures were excluded. Routine Cmin were measured in all patients before administration of the second or third dose. Additional gentamicin serum levels were measured $30 \mathrm{~min}$ (C30) and $4 \mathrm{~h}$ after the second dose in patients giving written informed consent. Data were analysed by non-linear mixed-effects modeling.

Results 165 patients (median age 34 days; IQR 15-56 days) were included in the study. A total number of 103 C30 and 166 Cmin measurements were available, respectively. C30 (mean $19.7 \mathrm{mg} / \mathrm{L}, \mathrm{SD} \pm 6.1 \mathrm{mg} / \mathrm{L}$ ) was $>12 \mathrm{mg} / \mathrm{L}$ in $94 / 103$ (91\%) and $\mathrm{Cmin}>2 \mathrm{mg} / \mathrm{mL}$ in $3 / 166$ (1.8\%) measurements. The PK model successfully predicted most C30 $>12 \mathrm{mg} / \mathrm{L}$ but performed poorly at the through levels.

Conclusions Our current gentamicin dosing regimen rarely leads to accumulation but most Cmax are above optimal range. The latter was successfully modelled. Although no evidence for a Cmax upper limit exists, toxicity has been associated with high drug exposure ${ }^{3}$. This calls for an adjustment of our dosing regimen using our PK model based on body height or weight in order to lower exposure. Further studies investigating the relationship between Cmax levels and clinical outcome and additional data for PK model testing are needed for validation.

\section{REFERENCES}

1. Ritz N, Bielicki J, Pfister M, van den Anker J. Therapeutic Drug Monitoring for Anti-infective Agents in Pediatrics: The Way Forward. Pediatr Infect Dis J. 2016:35(5):570-572

2. Chattopadhyay B. Newborns and gentamicin-how much and how often? J Antimicrob Chemother. 2002:49(1):13-16.

3. Touw DJ, Westerman EM, Sprij AJ. Therapeutic drug monitoring of aminoglycosides in neonates. Clin Pharmacokinet. 2009;48(2):71-88.

Disclosure(s) Nothing to disclose

\section{P74 RITUXIMAB EFFECT ON B CELL DEPLETION IN PAEDIATRIC PATIENTS WITH AUTOIMMUNE DISEASES A RETROSPECTIVE DOSE-RESPONSE ANALYSIS OF AN OBSERVATIONAL STUDY}

${ }^{1} S$ Pan $^{*},{ }^{1,2} \mathrm{H}$ Yu, ${ }^{3} \mathrm{~A}$ Surti, ${ }^{4} \mathrm{I}$ Cheng, ${ }^{1,4} \mathrm{SD}$ Marks, ${ }^{1,4} \mathrm{PA}$ Brogan, ${ }^{1,4} \mathrm{D}$ Eleftheriou, ${ }^{1,4} \mathrm{JF}$ Standing. 'University College London Institute of Child Health, London, UK; ${ }^{2}$ Novartis Pharmaceuticals AG, Basel, Switzerland; ${ }^{3}$ School of Pharmacy, University College London; ${ }^{4}$ Great Ormond Street Hospital for Children NHS foundation trust, London, UK

10.1136/archdischild-2019-esdppp.112

Background Rituximab is a chimeric IgG1 monoclonal antibody that depletes $\mathrm{B}$ cells for the treatment of several conditions including autoimmune diseases. It is not licensed for use in children but administered off-label. This study aimed to quantify the effect of rituximab on B cell depletion in children with autoimmune diseases and to optimise the dosing regimen.

Methods Electronic health record data were collected from a retrospective and anonymised study at Great Ormond Street 